Europe the

Spoil-Sport: On

the Europeans'

Reluctance

Towards

\section{Genetically Modified Food}

By Helge Torgersen, Jesper Lassen, Erling Jelsoe, Timo Rusanen and Torben Hviid Nielsen 1,2

Americans tend to see the difficulty in exporting crops grown from genetically modified plants to the European Union (EU) in terms of European protectionism. However, the action of the EU may also be seen as the outcome of its emphasis to reconcile regulatory discrepancies among member countries' political cultures and their respective framing of the "biotechnology problem." Public perception varies from country to country and has its impact on the regulatory practice. Since consumer trust in food regulation and in experts decreased after events like the BSE crisis, the EU

Helge Torgersen has a PhD in biology and was a researcher in molecular virology before he joined the Institute of Technology Assessment. Jesper Lassen is researcher at the University of Aalborg in Denmark. Erling Jelsoe is associate professor at Roskilde University, Denmark. Timo Rusanen has studied social sciences, public health and education and is researcher at the University of Kuopio, Finland. Torben Hviid Nielsen is professor of philosophy, affiliated to the Center for Technology, Innovation and Culture, University of Oslo, Norway.

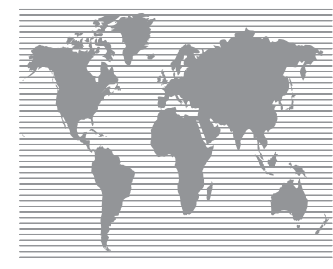

Cite as: Helge Torgersen, Jesper Lassen, Erling Jelsoe, Timo Rusanen and Torben Hviid Nielsen, Europe the SpoilSport: On the Europeans' Reluctance Towards Genetically Modified Food. J. BiolaW \& Bus., Vol. 3, No. 2, 2000.

(C) Copyright 2000 by The Joumal of BioLaw \& Business.
Commission has become extremely careful. However, the debate cannot be reduced to a simple risk controversy. The issue of food from modern biotechnology elicits deeper concerns with many Europeans about, for example, the relationship between regulation and the environment and about aspects of modernisation itself. Different rationalities compete for a more conservative (Blue) and a more environmentalist (Green) critique. In the light of other controversies, the biotechnology problem can even be interpreted as the "normal" case. The EU tries to accommodate social and political concerns implicitly while retaining the rhetoric of riskbased scientific argumentation. Nevertheless, as an answer to increasing critique, a more culturally determined rationality gains influence on practical decision-making.

\section{INTRODUCTION}

$\mathrm{O}$ ver the last years there was extensive debate in Europe over genetically modified (or, as some may prefer to call them, enhanced) crop plants and food products. In some countries, they were subject to unfavourable press campaigns, and the public, as measured by surveys, remained ambivalent to openly hostile, while those in medicine are considered benign. ${ }^{3}$ In particular, the import and the labelling of commodity crops grown from such plants in the United States (US) and in Canada caused a major stir. The EU appears reluctant to let these goods enter the internal market, although agreements on free trade would have obliged to allow the imports. ${ }^{4}$ US authorities have frequently argued that these commodities are only more competitivly produced due to the achievements of modern biotechnology, and that the EU is putting up undue barriers. They stressed the point that there is no scientific evidence of any risk to human health or the environment. This line of argumentation implying that only the result of the scientific risk assessment of the product counts, regardless of the process of production, was conceded valid in principle by the Europeans as well, ${ }^{5}$ nevertheless does the EU not grant permissions to such crops. Moreover, the EU has already succeeded to influence international bodies like the OECD with their policy-or, rather, non-policy, hitting "free trade and sound science." ${ }^{6}$ According to US officials, a major trade war is pending. ${ }^{7}$

So why won't Europe play ball? Are the Europeans really afraid of these crops, and if so, why? Are there hidden risks that were not detected by US scrutiny? Or is it because the European press runs havoc, inspired by non-governmental organisation (NGO) activism that lacks any scientific base, and regulators follow slavishly what they claim to be public opinion? Or are the objections only put forward in order to protect European agricultural producers and circumvent the world trade 
agreement? From an American, science and economy based point of view, there are no obvious reasons that could account for the EU behaviour other than sheer protectionism.

However, are things that easy? Or is the seeming reluctance of the EU bureaucracy only the surface, and the ripples are caused by deeper streamings invisible at first glance? In other words: is it only a controversy over alleged risks and economic benefits, or does the resistance to commodity crops from modern biotechnology point to more? Is it a failure of scientific experts to convince cowardly regulators and a deliberately misled public, or is it, in the end, a sign of a general European anti-modernism?

\section{THE EUROPEAN UNION- AN INTRICATE NETWORK}

Before we approach this question, we might ask whether there is such a thing as a common European stance at all that can be compared against the US view. We have to keep in mind that Europe consists of many countries, some of which have had long lasting and profound debates on biotechnology, whereas in others the discussion has barely begun. Furthermore, they all have very different regulatory styles and traditions. Already during the late Seventies and Eighties, when modern biotechnology was relatively new, these traditions lead to similar, but still different framings of the question of how to regulate modern biotechnology, not only between the US and Europe, but also among the various EU member countries. ${ }^{8}$ Although the facts were more or less the same, the way how the story of biotechnology was told differed considerably. ${ }^{9}$ From the very beginning, too, the various publics had different demands for the scope of regulation. For example in Germany and Denmark, this demand was much higher than in southern European countries or in Britain and France.

The EU Commission was well aware of this diversity when, in the late eighties, it formulated two Biotechnology Directives for Contained Use and for Deliberate Release each. ${ }^{10}$ One aim was to set up a least common denominator that all national governments would be obliged to follow in order to meet the overall aim of creating an internal market. ${ }^{11}$ As a concession to the critics, and as a means to prevent some member countries (as Denmark and Germany) from imposing further restrictions, a special guarantee was given. It allowed any member country to (temporarily) hinder a particular product from being placed on the domestic market if the country feared possible negative impacts on the health of its inhabitants or on its environment. However, scientific findings that provided evidence for such impacts had to be presented in due time. This was seen as a substitute for a genuine precautionary principle, which environmentalists and other critics had demanded as a counter-weight against a possible tour-de-force strategy by the industry to introduce products of modern biotechnology based on a reductionist understanding of risk. ${ }^{12}$

But the Commission's task was more complicated, since country differences did not cease to exist with the advent of the Directives. Although the economic aspects were in the forefront in many countries as well as in the Commission, a deeply rooted diversity in framing of the perceived problem that modern biotechnology poses remained, which lead to varying interpretations especially of the Directive on Deliberate Releases. The following examples may indicate how different the perspectives were and still are. ${ }^{13}$

\section{DIVERSITY TO BE RECONCILED}

In Britain, interference with individual rights (such as those of the farmers) is seen as problematic, a view that also influenced biotechnology regulation. Until recently officials seemed to be mainly concerned in letting innovation run its course. Although Britain relies extensively on external and independent expert knowledge in the decision-making process, secrecy is considered essential. This is in sharp contrast to Denmark, where the regulatory style is characterised by an effort to be relatively open. Denmark holds the view that state action is legitimate in order to protect future policy options (e.g. for a sustainable agriculture), and this leads to a more restrictive interpretation of the Directive. German authorities see the problem mainly in terms of regaining competetiveness which appeared to have been lost in a longlasting risk debate during the Eighties, when the country was regarded as reluctant to introduce genetic engineering. Norway, not a member of the EU but closely associated, interprets the problem as one of only supporting applications which foster sustainable development and are beneficial for society, without having a clear-cut definition on what that may be.

A good example for different interpretations provides the issues of GMO releases. Although there is a common framework defined by the Directive 90/220 for the assessment of release proposals. However, the basic understanding of how a risk assessment is to be performed as well as the interpretation of the Directive's criteria by the countries' competent authorities varied to some extent. ${ }^{14}$ What should be the ultimate points to consider? Until recently, the French authorities thought it was the perfect molecular characterization of the genetic construct-the applicant had to show that he or she is able to handle the stuff. The British were concerned about private property rights that may be violated by un- 
wanted side effects. The Dutch were afraid of effects on natural ecosystems (which, however, in the Netherlands are not really abundant). And the Danish did not want to put future options in agriculture into jeopardy. So the question remained of how to design a European policy that allows for a common market as well as for the necessary freedom of individual member countries. ${ }^{15}$

The picture gets even more complex if we consider the the relationship between individual countries within the EU Some have promoted and influenced the shaping of EU regulations (in the case of biotechnology these had been Britain and the Netherlands). In contrast, other countries were latecomers, which merely followed track and implemented the directives often reluctantly (like most southern European countries). And there are comparatively new EU members holding widely differing opinions. For example, in Finland the concern is actually to try to use modern biotechnology as a tool for R. \& D. industrialisation after the deep-going economic recession in the early 90's. Technology regulation is more or less left to the experts to everybody's seeming satisfaction. The traditional attitude of paternalistic protection in Finnish food regulation did not extend to other applications of biotech-there was no perceived problem. To the contrary, the Austrian authorities were horrified by public opinion, and they were quick to adopt the public rhetoric. In Austria there are many organic farmers, and an environmentalist interest to prevent the allegedly disadvantageous biotech applications in agriculture plays a role.

Further complexity was added by fairly recent policy changes in France and Britain, countries that had until then most outspokenly promoted agricultural biotechnology. In France, a series of political events including the installation of a new government led to a revision of the former promotive policy entirely based on technoscientific expertise. Recent developments in Britain have shown that public opinion does play a significant role in defining the national framing of the problem of how to regulate biotechnology. Britain experienced an unexpected media campaign that gave the government a hard time and forced it towards a far less promotive policy. Additionally, a wave of renewed public concern arose in previously sceptical countries like Denmark, and the rejection of agricultural biotech became consolidated in countries like Austria. In some countries that until then never had had a particular stance, like Greece, the climate for genetically altered plants became hostile as well. The policy shift of two big and important countries like France and Britain definitely changed the balance within the EU. It triggered a renewed emphasis to revise the Directive on Deliberate Release and resulted eventually in a virtual moratorium until the amended Directive would be enacted.
This regulatory loophole served to provide time until a new and stabel balance could be found.

Such outcomes of regulatory gridlocks within the EU are of course not confined to biotechnology. The problem with a unified Europe is that it still does not exist, even if there are common EU regulations in some fields. National peculiarities in the style of regulation, in the way of dealing with progress (or what some, but not all the people see as progress) and in the general way of living and thinking are recalcitrant to change and unification. Since almost every subject of regulation has to be negotiated between the member countries, time delays occurr and sometimes questionable compromises are reached in an attempt to muddle through. So it is no wonder that, for a spectator from outside, sometimes the EU may appear as a slightly incoherent supranational agency presenting somewhat awkward arguments from a scientific point of view, simply in order to cover internal discrepancies. This may contribute to the EU's image of bureaucracy and inefficiency that many Americans hold.

However, it is an over-simplification to consider Europeans and their institutions as just inefficient, hierarchical, over-bureaucratic, immobile and, worst of all, old-fashioned. The EU's internal variety provides opportunities for new solutions as well, as its institutions try to reconcile the differences. Even out of the seeming mess of current European biotechnology policy there is a chance that a new and more stable regulatory approach will emerge, which then will be considered more legitimate. ${ }^{16}$

\section{SCIENCE AND POLICY}

The EU Commission has strived to base policy decisions on scientific expertise as much as any state authority including the US Government did. In the case of modern biotechnology, only scientifically backed arguments of possible risk to human health and, recently, to the environment were accepted officially. Consequently, the role of the so-called Fifth Branch, the scientific advisors, has increased in political importance as in the US ${ }^{17}$ However, there are differences: in most European states there is a more consensual style of policy-making than the adversarial one prevalent in the US ${ }^{18}$ Consequently, Europeans leave more regulatory decisions via law-making to state authorities and less to the courts. This has some influrence on the argumentation patterns employed, and on the relevance of political arguments other than scientific evidence. So although-superficially-no criteria other than scientific evidence are considered valid, different points of view arising from uncertainty are considered at least partly legitimate, with the consequence that they simply cannot be neglected. 
In the community decision making process, where widely differing national (and lobby) interests have to be reconciled, arguments emerge that hardly fit into the scheme of risk as described in scientific terms, and that must be accomodated for political reasons. As a partial solution to this discrepancy, there is a tendency to reframe these arguments into terms of possible risks to human health and the environment. For example, it was argued that the recent amendment of the Release Directive 90/220 demanding a more comprehensive labelling was to increase transparency and consumer choice as an end in itself. In a Commission's press release however, the task of reducing risks was put to the fore: the new provision's aim was to prevent hazards for consumers at risk for allergic reactions, who must be given the opportunity to avoid certain products. ${ }^{19}$

Nevertheless, sometimes it becomes apparent that there are other things lurking behind the risk arguments. An example from a food controversy not related to genetically modified crops is the struggle over the use of recombinant Bovine Somatotropin to increase milk production. In order to prohibit the use of rBST, the EU relied mostly on the argument that there is a risk to the health of the cows treated with the hormone. This was considered a valid argument because in principle it is consistent with a scientific view. Although, in reality, the scientific evidence for harm was a bit shaky, the argument was more effectively challenged by WTO rules, since it relied on concerns for animal welfare more than on the proof of harm to human health. This is not a question of sound science, but the US could allege the EU of protectionist impediments of free trade, based on unscientific arguments-there is of course, at best, circumstantial evidence for a risk to human health. Steroid hormone application in meat production may be another case where the allegation of illegitimate market protection seemed to be substantiated from an US point of view. But that is not the whole story.

\section{TRUST AND THE IMAGE OF BIOTECHNOLOGY}

What seems to be protectionist at first glance is a strategy to stabilise a vulnerable European common market against the consequences of a loss of consumer trust in the effectiveness of the regulation. Hence, in the public, the Commission likes to be seen as upholding a kind of precautionary principle. The case of hormone treatment provides an example of how the Commission relied on arguments that took into account postulated harm but were, in the eyes of the US authorities, non-substantiated or, in other words, non-scientific, since (enough) conclusive evidence could not been brought forward.
Indeed, concerning public trust in regulators there are differences between the US and the mean of the EU countries,,$^{20}$ and the food regulators' fears appear justified as there have already been severe incidents. Consumer reactions to the Mad Cow Disease provide a lucid and very impressive example of what may happen to the internal market in case of public distrust. The events around the BSE case as well as a recent series of other food scandals had deep repercussions in the whole food sector and, by analogy, also influenced attitudes towards genetically modified crops and the way they are assessed. ${ }^{21}$ The trust in expert opinion suffered a severe blow in many European countries, mostly in those that are highly industrialised (but not in all. $)^{22}$

Keeping in mind the vast differences also in public opinion from country to country, we may nevertheless ask why genetically modified food has a far worse image in most European countries than in the US Two explanations are frequently put forward by advocates of biotechnology, namely that the European media influence public opinion by creating an emotional and negative image of biotechnology, and that people lack the scientific knowledge necessary to unmask such stories as fake. Indeed, in many countries, press coverage has been rather extensive over the last couple of years. Especially in Britain it is tempting to draw a causal link between a recent tabloid campaign and a public perception that has grown unfavourable. However, such an influence on public attitudes is not supported by independent media analyses, since the overall trend of European press coverage was in fact more favourable than that in the US. ${ }^{23}$ Do Europeans, contrary to Americans, know so little that they can be persuaded of hazards associated with genetically modified food? If we compare the average level of textbook knowledge, European citizens do even better in this respect than their US counterparts. However, their image of genetically modified food products is clearly more menacing.

What is it that separates such food products from conventional ones in many European consumers' eyes? Food products, on the one hand, are notoriously subject to scrutiny-you cannot do without them, and eating is always an act not only of consumption but also of ingestion. Since comprehensive testing is impossible, the demand for trust compensating the remaining uncertainty is very high. ${ }^{24}$ Whereas this is apparently no problem in the US, it has became difficult in the EU, as we will argue. Additionally, consumer attitudes towards food properties are clearly different in Europe and the US For example, whereas many health-conscious Americans consider cholesterol as a huge risk and consequently appreciate products processed to reduce fat, their Euro- 
pean counterparts tend to think of such produce as artificial and prefer natural, "unadulterated" ones.

This highlights the fact that for many Europeans especially from northern countries the term food quality has a wider meaning. It does not only refer to material properties like taste, safety, nutritional value, etc., but also to more immaterial qualities like the way of production and its consequences for the environment, animal welfare, or even ethics. In particular, products of modern biotechnology tend to stand as a proxy for the good and evil of modernisation itself. ${ }^{25}$ So they are subject to scrutiny for two different reasons: Not only must they be harmless or even beneficial, but they also have to prove that modernisation is a good strategy to follow, and not a one-way cul-de-sac without escape. This is exemplified by two basic demands that such products have to meet in the European public: i) they must not put human health at risk, as well as provide a benefit to the consumer; ii) their production must not have deleterious side effects especially with respect to the environment; on the contrary, there should possibly be an improvement as compared to traditional ways of production-if ever possible.

The problem of total food safety suffers from the paradox that scientific evidence may be overturned by further experience, which means that there is no proof for the absence of anything, not least of a risk. However, at least theoretically there may be a proof for the presence of some unwanted effects. Evidence thus is skewed-you will never get the proof of safety, and uncertainty prevails. There are only two ways to circumvent the problem: either there is a solid trust in those who produce and assess the food, or there are obvious benefits for the consumer that outweigh possible risks.

To many consumers, however, trust in producers and regulators is a problem. They draw analogies beween genetic modification and other techniques of modern industrialized production systems in agriculture and food processing. Several European countries have seen debates about the consequences of these systems in recent years, where experts have tended to downplay the risks. Salmonella in food, pesticides in drinking water, animal husbandry that resemble large scale factories, and, especially in Britain, the problem of BSE act as a frame of reference. As to the benefits, it appears difficult for food producers to convince European consumers that they will profit from modern biotechnology in terms of better or cheaper products. Many people perceive the benefits to lay predominantly with the producers and the risk with the public. ${ }^{26}$

Consequently, many retail chains have cleared their shelves from any product that contains genetically modified ingredients in an attempt to avoid consumer retaliation. In general, the future of food products from modern biotechnology looks not too bright at the moment. Industry is reluctant to really press on with a heavy lobbying campaign for two reasons. Firstly, it is difficult to devise a strategy that caters for all the different European countries with their particular publics, as well as for the EU institutions. Secondly, since most of the big players are also engaged in other areas of biotechnology, the agricultural sector as a hot potatoe is not to their main concern. Until recently in EuropaBio, the industry's lobby organisation, "there (wasn't) a real concsensus that defending biotechnology in general is something that's in everybody's interest." 27 A recent advice from the Deutsche Bank to their clients not to invest into food biotechnology since consumers react negatively may be indicative for the investors' reluctance against, or even slow retreat from, agricultural biotechnology in Europe. ${ }^{28}$

\section{COMPETING RATIONALITIES}

We may have a closer look at the question why products of modern biotechnology bear such a special burden in most European countries and especially with certain groups of the public. As we have seen, to many consumers the issue of modern biotechnology is not only concerned with specific scientically defined risks, but in a broader sense with the way in which we regulate the interaction between humans and the natural and even the cultivated environment-and traditional agriculture is dear to many Europeans. Consequently, there is a strong social and political dimension.

If we look at such wider arguments, we may group them, roughly, into three categories of competing rationalities and call them the Blue Critique, the Green Critique and the Entrepreneur's promotion. ${ }^{29}$ The Blue Critique originates from the conservative end of the political spectre. It has to do with a general disbelief in the blessings of modern civilisation and the commercialisation of everything, accompanied by a rejection of the abolishment of the supernatural, with a deep-hearted conviction that there are borders set by God that must not be trespassed.

The Green Critique's origin is more politically left. It concerns the environment that is seen as fragile and that must not be endangered by commercial activities of doubtful benefit for society as a whole. Also, the distribution of advantages and disadvantages arising from the applications of modern biotechnology is too skewed: only those who already have will gain.

The Entrepreneur's promotion favours modern biotechnology and concedes the appropriateness of restrictions only where there is evidence for or, at least, a 
strong plausibility of risk. It stresses the freedom of enterprise and the necessity of innovation. This goes hand in hand with a reminder that Europe may loose competitiveness when indulging into non-risk based arguments. Although these types may differ from country to country as well as over time, they exist almost everywhere and have put their mark on many a debate about biotechnology regulation.

An example of the competition between the Green and the Entrepreneur's rationality is the question of labelling already addressed. The Blue may consider such products as morally flawed, so that they must be labelled in order to be avoided. The Green may be concerned about consumer rights for their own sake: You should know exactly what you are buying, which may include information on how the product was generated, regardless of whether there is a risk associated with it or not. The one to decide is yourself. The Entrepreneur's argumentation is that of risk prevention: If you buy a food product that could be hazardous to your health, then you should know. But if a risk is improbable, labelling is inappropriate-the one to decide is the expert. Labelling may even be a disadvantage for the product on the market place, wich is a risk for the producer. Hence, competing rationalities may perceive an apparent objective risk-based labelling strategy to be skewed towards the producers' interests.

\section{CONCLUSION: THE PROBLEM AS THE NORMAL CASE}

Coming back to European biotechnology regulation, it is obvious that finding a solution suitable for all countries and groups is no simple task. The EU Commission tries to uphold a scientific and economic rationality in order to overcome internal non-tariff trade impediments, but the problem is deeper and more complex. Not only is it a matter of reducing risks or preventing hazards, it is also a question of how modernisation is seen, who benefits from the advantages and who has to bear the burdens. Thus, the perceived biotechnology problem currently observed in Europe is part of the well-known debate about risks in a modern society. Such controversies have been going on for decades both in Europe and also in the US, where they at times have been even more vivid. They were mostly labelled as pure risk issues and fought out with a lot of scientific expertise from both sides.

But, after all, is there such a thing as a "pure" risk controversy? Questions of equity, distribution and fairness, which are clearly non-scientific in their nature, always flagged up. Although different subjects cannot be compared on a one-to one basis, a general comparison of the ways controversies were carried out in the US and in Europe reveal elements beyond scientific argumentation. Not only are there differences in the juridical systems, but also in the perception of the state's agenda, for example in the question whether a particular risk is considered publicly relevant. One crucial determinant in the US is whether a risk is deliberately imposed on individuals offending their rights. ${ }^{30}$ For example, smoking put non-smokers sitting next to a smoker at risk, so legal action is possible. In contrast, radon, a major health hazard, has been publicly debated, but was not of a concern to policy because nobody imposes a risk on the individual. In Europe, concerns are less dominated by the question whether a risk is imposed and somebody being liable, but rather whether the risk is possible and how the state may protect its citizens. Clearly, differences between European countries are profound also in this respect, with Britain coming closest to the US in the focus on individual rights. We consider such differences as ultimately linked to the respective political cultures.

Although for example controversies over waste treatment facilities, as hazardous waste incinerators or superfund sites in the U.S, have been a major cause of recurrent public debate and policy initiatives also in Europe, ${ }^{31}$ US and European controversies differ often in the issues and in the point in time they arise. Automobile safety and smoking have been addressed much earlier in the US, as well as releases of GMOs (the Ice-minus bacteria), which has become a non-issue now. Genetic testing is considered a current field of conflict mainly in the US due to the potential impact on personal insurance and employment. In Europe, testing is of much lesser concern than GMO products. This reflects obvious differences in the social security systems, but also in the attitude towards individual privacy.

The US experienced even food controversies where scientific evidence was doubtful, as in the debate over food additives and pesticide (Alar) residues on fruit, although they never reached the level of, e.g., the European BSE scandal. Notwithstanding the different attitudes towards food properties and new technologies, if US public perception of possible risks would put a questionmark to the current positive emphasis on food biotechnology as an entrepreneurial opportunity, a fierce labelling debate could arise. Some recent policy lawsuits already point in that direction. ${ }^{32}$ As most parties agree, agricultural biotechnology could have, or is about to have, a profound influence on the way we produce and consume our food. Hence, with regard to its potential societal impact, one may rather consider the exemption of modern biotechnology from the risk and modernisation debate, as observed in the US until now, as the anomaly, and the presence of a biotechnology problem in Europe as the normal case. 
The obviously wider scope of the debate beyond simple risk determination may also be the reason for the observed backlash for agricultural biotechnology in Europe during recent years. As the fates of the first genetically modified commodity products show, the interpretation that only scientific risk arguments are valid has been challenged. Regulators, forced to find an answer, have to react to the challenge. Currently there is a tendency to open up a backdoor in that-although not openly expressed-also a more culturally related rationality may be taken into account. This rationality concedes that there are, besides scientific proof, other more subjectively or even individually determined qualitative criteria which may serve as a base for a (temporary) policy in a particular area.
Such a development is hard to understand and may be a disappointment to those who wish to see in place exclusively evidence-based, scientifically sound and rational regulations not entailing exceeding costs and, most important, promoting free trade-if there ever existed such a thing. Consequently, tensions may arise between the EU with its many cultures and countries, and its partners advocating a purely scientific and economic view of the world like the US But after all, even the seemingly rational style of regulation in the US is the outcome of a specific national culture and has developed under certain historical conditions. ${ }^{33}$ So let us try to better understand the different conditions and cultures instead of accusing each other to be "irrational." There is definitely more than one single rationality.

\section{ENDNOTES}

1 This article is based on a paper given at the 1998 annual Meeting of the American Association for the Advancement of Science, 12-17 February, Philadelphia, Pennsylvania.

2 The authors are members of the Concerted Action Groups "Biotechnology and the European Public" and "European Debates on Biotechnology: The Dimensions of Public Concern " funded by the European Community (Contracts nos. B104-CT95-0043 and B104-98-0488). HT was supported by a grant from the Austrian Fonds zur Fřrderung der wissenschaftlichen Forschung (no. P11849-SOZ) and by the Austrian Federal Ministry of Science and Traffic (GZ 650.275/2-III/2a/99).

3 Biotechnology and the European Public Concerted Action Group (BEP), Europe ambivalent on biotechnology, Nature 387, 26 June 1997, 845-847 (1997).

4 J. Fox, US to EU: Please, pass the maize, Nature Biotechnology 16:1, 11 (1998).

5 H. I. Miller, Concepts of risk assessment: the "process versus product" controversy put to the rest, in H. J. Rehm, G. Reed (eds.), Biotechnology (2nd ed.), vol. 12: legal, economic and ethical dimensions, Verlag Chemie, Weinheim/New York (1995).

6 H. J. Miller, Nasty taste from G-8 GM food policy, Nature Biotechnology 17, 8, 730, August 1999

7 "The EU's fear of bioengineered foods ... is the single greatest trade threat that we face." Stuart Eizenstat, nominee for a leading job at the US Treasury Department, testifying before the US Senate on June 29, 1999.

8 S. Jasanoff, Product, process, or program: Three cultures and the regulation of biotechnology, in M. Bauer (ed.), Resistance to new technology, 311-331, Cambridge University Press (1994).

9 H. Gottweis, Governing Molecules. The Discoursive Politics of Genetic Engineering in Europe and the United States. MIT Press, Cambridge, MA. (1995).

10 Council of the EC, Directives 90/219/EEC on the Contained Use and 90/220/EEC on the Deliberate Release of Genetically Modified Organisms Into the Environment from 23. 4. 1990, ABl L 117/15, Brussels (1990).

11 M. Cantley, The Regulation of Modern Biotechnology: A Historical and European Perspective, in D. Brauer (ed.), Biotechnology vol. 12: legal, economic and ethical dimensions, 505-681, Verlag Chemie, Weinheim/New York (1995).

12 J. Hunt, The social construction of precaution, in T. O'Riordan, J. Cameron, Interpreting the precautionary principle, 172-182, Earthscan, London (1994). The "reductionist" approach can be paraphrased by a quote from the US National Research Council's Field testing Genetically Modified Organisms: Framework for Decisions (National Academy Press, Washington D.C. (1989): "With organisms modified by molecular methods, we are in a better, if not perfect, position to predict the phenotypic expression."

13 J. Durant, M. Bauer, G. Gaskell (eds.), Biotechnology in the Public Sphere, Science Museum, London (1998).

14 L. Levidow, S. Carr, R. von Schomberg, D. Wield, Regulating agricultural biotechnology in Europe: harmonization difficulties, opportunities, dilemmas, Science and Public Policy 23,
135-157 (1996). See also the country reports in this special issue on biotechnology regulation.

15 R. v. Schomberg, An Appraisal of the Working in Practice of the Directive 90/220/EEC on the Deliberate Release of Genetically Modified Organisms, STOA, European Parliament, Luxembourg (1998).

16 supra note 15.

17 S. Jasanoff, The Fifth Branch: Science advisors as policymakers, Harvard University Press, Cambridge, MA. (1990).

18 supra note 8.

19 European Commission, The European Commission has decided to propose further labelling of genetically modified organisms, press release IP/97/269, Brussels (2. April 1997).

20 G. Gaskell, M. Bauer, J. Durant, N. Allum, Worlds apart? The reception of genetically modified food in Europe and the US, SCIENCE 285, 384-387 (16. July 1999).

21 supra note 13.

22 Interestingly, in countries like Finland, the experts' role seemed to be unaffected and they are still considered to be objective and rational. This is just another facet of European divergence.

23 supra note 20.

24 For the relationship between knowledge, uncertainty and trust see N. Luhmann, Trust and Power, Wiley, Chichester (1979).

25 supra note 13.

26 This is contrary to the situation with pharmaceuticals and other medical applications which are broadly accepted in Europe.

27 E. Dorey, EuropaBio unit created to boost agbio defense, Nature Biotechnology 17, 7 631-632 (July 1999).

28 According to the Guardian from 25.8.1999, an internal report into GM food conducted by Deutsche Bank has been published by the Minnesota-based research group The Institute for Agriculture and Trade Policy. The report, published last month under the heading "AgBiotech: Thanks, But No Thanks" says: "GMOs are being demonised by their opponents. What food manufacturer will 'take a bullet' for GMO corn in the face of such controversy?"

29 T.H. Nielsen, Behind the color code of "no, "Nature Biotechnology 15, 7, 1320-1321 (1997).

30 J. Linnerooth-Bayer, IIASA Laxenburg, personal communication; see also supra notes 8 and 9 .

31 B. Davy, Essential Injustice, Springer Wien / New York (1997).

32 J. L. Fox, FDA, activists seek judgements in food policy lawsuits, Nature biotechnology 17 8, 746-747 (1999).

33 supra note 8 